\title{
False recognition produced by laboratory-established associative responses
}

Sixty-four Ss learned one of two paired-associate (PA) lists (A-B or $\mathrm{C}-\mathrm{B}$ ) and then transferred to a 100-word recognition list (RL). During RL Ss were required to indicate as each word was shown whether or not that word had been shown earlier in RL. The stimulus words from one of the PA lists (A words) appeared in the first half of RL. Both the natural language associates of the $A$ words $\left(A^{\prime}\right)$ and the $P A$ response words (B) appeared in the second half of $\mathrm{RL}$. There was a significant interaction indicating more errors were made to $B$ words than to $A^{\prime}$ words following $A-B$ learning, but the opposite obtained following $C-B$ learning.

Underwood (1965) has demonstrated that pre-experimental language habits can influence recognition error rates. In a long series of words the probability that Ss would incorrectly indicate that a given word had appeared earlier (false positive) was higher if that word was preceded in the list by words associatively related to it. For example, presenting chair early in the list increased the number of false positives to table, which appeared later in the list. It was suggested that chair elicits table as an implicit associative response (IAR), therefore when table is actually presented it has some prior frequency of occurrence. This prior frequency increased the likelihood that Ss would confuse table with words which occurred earlier, as compared to control words which were not associatively related to earlier list words.

The purpose of the present study was to determine if implicit-associative-response confusion can be produced by verbal habits acquired in the laboratory. Verbal habits were acquired by paired-associate (PA) training. The recognition series followed PA training. It was of interest to determine if presenting the PA stimulus words early in the recognition series would lead to an increased false-positive rate to PA response words, which were presented later in the recognition series.

\section{Method}

Ss first learned a PA list and then transferred to a 100-word recognition list (RL). There were two groups, each learning a different PA list. All Ss received the same RL. The PA and RL lists were presented by means of a $16 \mathrm{~mm}$ film-strip projector. The PA list consisted of 12 pairs presented for four study-test trials at a 6 -sec. rate. During PA learning Ss had a 4-page booklet, each page containing the numbers 1-12. On the test trials each stimulus word was shown on the screen, and Ss had to record the corresponding response words in the appropriate num- bered spaces. After each test trial Ss turned to the next page in their answer booklet. One group learned 12 "A-B" pairs, and a second group learned 12 "C-B" pairs. The two groups had different stimuli but common response words.

Following PA learning both groups were presented with the same 100-word RL, with each word presented successively at a 6-sec. rate. During RL Ss indicated as each word was presented, whether or not that word had appeared earlier in RL. Each A word (PA stimuli for Group A-B) was presented twice in the first half of $\mathrm{RL}$. In the second half of the list each $A^{\prime}$ word (primary normative associates to $A$ words) and each $B$ word (PA response terms) were presented. It should be noted that in $R L$ neither $C$ words nor the words for which B words were primary associates were presented. The A, B, C, and A' words were selected from the Palermo \& Jenkins norms (1964). The A and C words were selected randomly from the stimulus words, and the $B$ words were selected randomly from the primary responses of the remaining unselected stimulus words. The $A^{\prime}$ words were the primary associates to the A words.

There were four classes of words in the second half of RL. There were $12 \mathrm{~B}$ words, $12 \mathrm{~A}$ ' words, 12 words which had actually appeared in the first half of the list (R), and 14 neutral words (N), words occurring for the first time and presumed to be neutral to other list words. There was approximately a 5-min. pause between PA and RL during which time PA answer sheets were collected, RL answer sheets were handed out, and $\mathrm{RL}$ instructions were read. There was no pause between the two halves of RL.

The Ss were introductory psychology students at Northwestern University. There were 32 Ss in each group, and the data were collected in six group sessions. The Ss volunteered for the various sessions, and the sessions were assigned to treatments at random.

\section{Results and Discussion}

All Ss made perfect scores on the fourth trial of PA learning. The mean number correct over four trials for Group A-B was 46.16 and for Group C-B, 44.94. The difference between groups was not significant, $F=2.49, \mathrm{df}=1 / 62$.

The data of major interest were the number of errors made to critical words in the second half of RL. The mean number of errors to $A^{\prime}$ words and $B$ words for Group A-B was .47 and 4.47, respectively. The mean number of errors to $A^{\prime}$ words and $B$ words 
for Group C-B was 1.53 and 88 , respectively. A 2 by 2 analysis of variance was used to compare the errors made to $A^{\prime}$ words and $B$ words. An arc sin transformation was made on these error scores to remove heterogeneity of variance. The analysis revealed that all effects were significant. The two main effects indicated that Group $A-B$ made more errors than Group $\mathrm{C}-\mathrm{B}, \mathrm{F}=14.17, \mathrm{df}=1 / 62, \mathrm{p}<.01$; and more errors were made to $B$ words than to $A^{\prime}$ words, $F=31.66, \mathrm{df}=1 / 62, \mathrm{p}<.01$. There were more errors to $B$ words than to $A^{\prime}$ words for Group $A-B$, but Group $C-B$ made more errors to $A^{\prime}$ words than to $B$ words, resulting in a significant interaction, $F=95.41$, $\mathrm{df}=1 / 62, \mathrm{p}<.01$. It appears that learning the $A-B$ associations in the laboratory resulted in $B$ words becoming the dominant IARs to A words. The failure to observe this effect following the learning of $\mathrm{C}-\mathrm{B}$ would seem to suggest that general confusion resulting from having presented $B$ words earlier (during PA learning) was not responsible for the increased error rate to $B$ words.

The mean number of correct responses on the second half of RL was compared for the two groups. Group A-B had a mean of 42.97 and Group C-B had a mean of 44.31. The difference between groups was not significant, $F=2.25, d f=1 / 62$. The greater error rates to $B$ words for Group A-B were compensated for by the slightly greater error rates for Group C-B to the remaining three classes of words in the second half of RL. Group C-B, as compared to Group A-B, averaged more errors to $A^{\prime}$ words (1.53 vs. .47), $R$ words (1.78 vs. 1.56$)$, and $\mathrm{N}$ words $(1.50$ vs. .53).

\section{References}

Palermo, D. S., \& Jenkins, J. J. Word association norms. Minneapolis: University of Minnesota Press, 1964.

Underwood, B. J. False recognition produced by implicit verbal responses. J. exp. Psychol., 1965, 70, 122-129. 